$\Longrightarrow$ Taylor \& Francis Taylor \& Francis Group http://taylorandfrancis.com 


\title{
QUESTION BASED INSTRUCTION (QBI) PROMOTES LEARNERS' ABILITIES TO ASK MORE QUESTIONS AND EXPRESS OPINIONS DURING GROUP DISCUSSIONS
}

\section{Yoshinori Oyama and Tomoko Yagihashi}

\begin{abstract}
Summary
Generating questions is a fundamental skill for critical thinkers. This chapter describes Question Based Instruction (QBI), a teaching method in which classroom lessons are based on learner-generated questions; subsequently, learners discuss the questions they have generated. This method was used in an elementary school class, and measurements were taken to assess students' abilities to ask questions and express opinions. The results of the data analysis indicate that QBI promoted increases in students' utterances and questions during group discussions. This chapter also explains the teaching steps required to carry out QBI and discusses reasons for its effectiveness and its potential applications.
\end{abstract}

\section{Benefits of developing learners' questioning skills}

The generation of questions is an essential skill for learners on the path toward becoming lifelong learners. As Oyama (2017) explained, if learners can generate their own questions, they will seek answers; thus, a continuation of inquirybased learning will likely be facilitated. For example, when learners read some study material and come up with questions, and an instructor asks those learners to share and discuss the questions with each other, their understanding of the material can deepen. Additionally, through the inquiry process, new questions arise and inquiry-based learning can continue to deepen knowledge. Based on their questions, learners communicate with each other to tackle issues in a cooperative manner and, through that process, their commutation skills can improve. Moreover, to generate questions, learners must see things critically; therefore, their critical thinking skills can also be developed. 


\section{Teaching questioning skills}

In the late 1980 s and early 1990 s, King $(1989,1991,1992)$ led research on question generation and lecture comprehension. For instance, King (1989) trained college students to generate questions on lecture content. Comparing the questioning strategy with a review of lecture content, she reported that use of the questioning strategy resulted in better lecture comprehension.

To better understand the most important points that questioning studies have revealed, Rosenshine, Meister, and Chapman (1996) conducted a meta-analysis of 26 studies on question generation. They reported that one effective training activity is the use of "questioning stems" (e.g., fill in the blanks, as in: "What is the main idea of ___?," "How is____ related to ____? ), which are designed to prompt the generation of useful questions. They also noted that it is effective to use "signal words" (e.g., provide learners with the initial key words of questions, such as "who," "what," "where," "when," "why," and "how").

Concerning intervention studies to promote question generation, Ikuta and Maruno (2005) assisted elementary school pupils to generate questions according to a "three-step instruction" method they developed. For the first step, an instructor helped pupils recognize gaps between what they knew and what was in the study material or what other classmates said. In the second step, the instructor assisted pupils in generating appropriate questions by providing a format, such as "What are the advantages and disadvantages?" In the third step, the instructor assisted pupils in stating their questions. If the wording of questions was unclear, the instructor helped the pupils to modify the expressions used in the questions. After the three-step instruction, pupils" motivation to "want to know more" was found to be higher than at their pre-training stage.

Yuzawa (2009) categorized junior high school students' questions as follows: confirmation of learning content (e.g., "What is GDP [Gross Domestic Product]?"), the structure of learning content (e.g., "Why did European countries form the EU?"), and the application of learning content (e.g., "Why did countries A and B sign the Free Trade Agreement?"). Then, he asked students to generate questions on the subject material, and to categorize their questions according to the above. Yuzawa reported that most of the students' questions were of the "confirmation of learning content" type. Only a few students generated questions about "application of learning content." Regarding this point, Yuzawa (2009) intervened by showing students model questions. For example, when an instructor wants students to generate questions for the application of learning content, the instructor shows a model question - such as, "How can we apply this to the real world?" Then, students are asked to generate similar questions. Yuzawa also reported that training in questioning has a "trans-subject" effect. For example, in a literature class, students were trained to take other people's perspectives and generate questions, such as "What would Alice from Alice in Wonderland say if she visited our society?" In a history class, the same students were later observed to ask questions such as "What would the Roman emperor, Caesar, say if he observed the modern political system?” 


\section{Under what conditions do learners generate questions?}

Instructors need to understand the cognitive processes inherent in learners' generation of questions and provide training tips to promote learners' questioning skills. Therefore, this section examines the processes for generating questions from the perspective of cognitive psychology.

\section{From the researcher's perspective: Cognitive models of generating questions}

Regarding this topic, Otero (2009) provided an insightful review of cognitive models that have been proposed for question generation. Three hypotheses relating to such models have been proposed: "knowledge deficit," "knowledge clash," and "obstacle + goal."

\section{Knowledge deficit hypothesis}

According to the knowledge deficit hypothesis, "a question is conceived as driven by a lack of knowledge" (Otero, 2009, p. 48).

However, the knowledge deficit hypothesis (Otero \& Graesser, 2001) cannot be regarded as automatic. Sometimes, people cannot detect their knowledge deficit on their own. However, if others ask them questions, they notice gaps. For example, when tourists come to a country and ask locals, "What's the population of your capital?," most people do not know the answer and recognize their knowledge deficit.

Another way to raise consciousness of the knowledge deficit is to employ questioning stems. As mentioned previously, questioning stems comprise a list of questioning formats, usually with blanks or missing parts. The blanks are to be completed with words from students' reading materials (e.g., "What is a new example of ____?”). King (1992) used questioning stems to stimulate learners to generate questions, and their comprehension improved, in contrast with learners who did not generate questions.

\section{Knowledge clash hypothesis}

However, the knowledge deficit hypothesis is not the only explanation for question generation. In Miyake and Norman's (1979) study, learners were asked to say aloud all the questions and thoughts that occurred to them while they were learning. They reported that with the easier material, novice learners (who possessed less knowledge) asked more questions than trained learners; however, with the harder material, trained learners (who possessed more knowledge) asked more questions than novice learners. This result suggested that "knowledge gaps" alone cannot explain question generation.

Based on Miyake and Norman's (1979) finding, Otero and Graesser (2001) proposed the "knowledge clash" hypothesis. According to Otero and Graesser, 
people generate questions when they detect an incongruency between their background knowledge and the information they encounter. They hypothesized that readers with more knowledge will ask more questions after reading more difficult materials because there would be a greater probability of inconsistencies occurring between their internal knowledge and the external information that is provided in the difficult material. In contrast, readers with less knowledge would ask fewer questions after reading the difficult material because they would be less likely to detect inconsistencies between that material and the limited knowledge they possess (i.e., if they do not know much about it, there would be a low likelihood of inconsistencies occurring).

\section{Obstacle + goal hypothesis}

Otero (2009) suggested that there was a third hypothesis that explained question generation - that is, the "obstacle + goal hypothesis." Otero claimed that question generation is driven by recognition of obstacles when attempting to attain a particular goal. For example, when individuals read materials to understand it, the goal is "understanding the material." When readers encounter new vocabulary and do not know the meanings of some of those words, they encounter obstacles, and questions such as "What does mean?" are generated.

Therefore, it is important for teachers to design their instruction so that learners would encounter certain obstacles toward reaching their goal: that way, they would generate questions that are authentically meaningful to them.

Regarding this point, the Japanese researcher Hosoya (1977) proposed "operation provoking questions" in which an instructor ask learners "How can you/we [do or achieve something] as [quality or level of achievement] as possible" type of questions. For example, in an elementary school science lesson on electromagnets, an ordinary instruction is "make your own electromagnet." However, when using "operation provoking questions," the teacher asks, "How can you make an electromagnet as strong a magnet as possible?" This kind of question ignites learners' intellectual curiosity as they try to overcome obstacles by asking additional questions (e.g., "How can we make the electromagnet strong?" and "What makes the electromagnet strong?") to achieve the goal. Therefore, from Otero's viewpoint, "operation provoking questions" establish a goal for learners, and by generating further questions, they try to overcome obstacles to achieve the goal.

\section{Question generation requires an understanding of the material and cognitive gaps}

Students generate questions based on the three hypotheses of Otero (2009) knowledge deficit, knowledge clash, and obstacle + goal. However, developing questioning skills requires learners to have an adequate background knowledge of the subject. For example, according to Otero's knowledge deficit hypothesis, 
it is crucial for learners to have an adequate amount of background knowledge to be able to detect the deficit. Likewise, such background knowledge is necessary for learners to notice the gaps between what they have learned and what they are about to learn. Therefore, for Question Based Instruction (QBI) to fully function, it is necessary to ensure that learners possess basic knowledge first before asking them to generate questions.

Some instructors rush in asking learners to generate questions. In extreme cases, at the beginning of the lesson, instructors already ask learners to, "Make questions; we are going to discuss and answer them later on." However, it is most often the case that learners cannot generate quality questions worth discussing or even answering. Based on the knowledge clash hypothesis by Otero and Graesser (2001), for learners to generate questions they must comprehend materials presented in the lesson. On this point, Graesser and Olde (2003) examined how participants in their study experienced cognitive disequilibrium, triggered by contradictions, anomalies, obstacles, salient contrasts, and uncertainty, and how their level of understanding of the subject matter might influence the quantity and quality of the questions they produced. The results showed that participants with deep comprehension did not ask more questions; however, they generated a higher proportion of good questions. Thus, the researchers concluded that participants' levels of comprehension affected the quality of the questions they generated.

Therefore, instructors should initially ensure that learners in their classes comprehend the material for which questions will be generated. Otherwise, there would be no discrepancy or incongruency between learners' prior knowledge and information presented in the lesson, and the learners could only create factual questions or ones that require definition of technical terms (e.g., "What is A?"). In contrast, learners would be able to generate more thought-provoking questions (e.g., "Considering Britain's situation in the 1940s, what kind of diplomatic strategies would you have taken if you were in Churchill's position?") if they are first required to obtain background knowledge about the topic under consideration (e.g., World War II and the situations in England and other countries at that time).

\section{Problems with previous question generation practices}

Based on descriptions in previous sections regarding the cognitive processes involved in question generation and the instructional practices often used for facilitating such generation in learners, this section considers two of the main problems or limitations of those practices.

\section{Learners' understanding of the material is not always guaranteed}

Some practices have as an underlying assumption that learners already have sufficient knowledge or fully understand the material they are dealing with. However, this assumption is not always correct. Learners with little knowledge or those 
who have only a superficial understanding of the material can only generate surface-level questions. According to findings of Otero (2009) mentioned in the previous section, in order for learners to experience cognitive gaps, it is crucial that they have enough knowledge about the material on which questions are to be based. Only under these conditions can learners contrast their understanding of the material with their background knowledge; if they detect gaps between the two, they generate questions. Therefore, it is crucial for the instructor to take concrete steps that would ensure learners fully understand the material for which they are expected to generate questions.

\section{Learners' generated questions are not effectively used}

Almost all practices that have been developed in Japan and in other parts of the world are focused on the generation of learners' questions. However, how they use the questions in teaching is not always clear. Learners become demotivated if their questions are not used and they may think question generation is useless. Teaching practices for generating questions should put more emphasis on the application of learners' questions in a lesson. Thus, learners will understand why they need to create questions. Possible ways to use learners' questions are group discussions about the questions, the formation of pairs for answering questions, and inquiry-based learning.

\section{Question Based Instruction (QBI)}

This section presents a possible solution to those problems and limitations: QBI. This method emphasizes that learners understand the material in the first part of the lesson (steps 1-3). In addition, by contrasting their preexisting knowledge and new information provided in the lesson, learners experience cognitive gaps and therefore generate questions. In the second part of the lesson (steps 4-8), an instructor leads a classroom activity based on the questions learners generated so that they can experience the efficacy of the questions in deepening their understanding of the material. Details of QBI are shown below.

\section{First part of the lesson}

1. The instructor explains the study material to learners.

2. The instructor ensures that the learners understand the material by the instructor asking questions and writing a summary on the board. In some cases, the instructor has learners explain the material in pairs to check their comprehension.

3. The instructor asks learners to generate questions about the material.

Second part of the lesson

4. The instructor forms groups based on the questions learners generated. 
5. The instructor asks learners to discuss the questions they generated.

6. The instructor collects opinions from each group and shares them with the class.

7. The instructor asks the main question he/she prepared for the entire class (as what learners want to discuss and what the instructor wants the learners to discuss sometimes differ, so this part enables the instructor to draw learners' attention to what he/she considers important).

8. The instructor summarizes key points from the lesson.

One important feature of the instruction outlined above is learners forming groups based on similar questions; their questions are therefore "shared" in the group and discussed with others who have related concerns. Sharing a learner's own question in the group may have a positive effect on the learner's motivation to engage in the lesson and communicate with other learners effectively. This activity may also give learners the impression that the lesson is enjoyable or exciting. Additionally, learners speak out more during group discussions when the topic is shared and relevant to their questions. However, only a few studies have examined the effects of sharing questions and having a group discussion based on learners' questions. Therefore, Study 1 (described below) explored the effect of generating questions and using those as essential components of the group discussion topic.

\section{Study 1}

The objective of Study 1 was to examine the effect of QBI on the amount and quality of utterances during a discussion and the way it motivates learners to engage in the lesson.

\section{Method}

\section{Participants}

Ninety-one 3rd-graders (elementary school pupils, 45 males and 46 females), participated in this study. Participants were from three classes (class $1=31$ pupils, class $2=29$ pupils, class $3=31$ pupils). Each class received different instructions (randomly assigned).

\section{Materials}

The Japanese folktale, "Naita Akaoni" (“The Red Ogre Who Cried”), written by Hirosuke Hamada, was chosen for its simple storyline; thus, it was anticipated that pupils could easily comprehend the content. Moreover, it includes numerous points that pupils may wish to discuss.

The story is about a red ogre who wants human friends. A blue ogre proposes a plan to the red one. According to the plan, the blue ogre, assuming the role of a human enemy, vandalizes the village where humans live, and the red ogre beats 
up the blue one to win humans' trust and friendship. However, one day, the red ogre receives a letter from the blue one that says, "Dear Red Ogre, I hope you have been having wonderful days with the humans. If you meet with me again, the humans would doubt your sincerity, so I won't meet you again ever. Take care of yourself and have a great life. Your friend forever, Blue Ogre." The red ogre cries and cries after reading this letter.

\section{Instructions}

In this study, the three classes received different instructions to examine the effect of variations in those instructions on learners' engagement in the group discussion and their impressions of the lesson.

For pupils in a "generate questions" group (class 1), in the first period of the lesson (45 minutes), the instructor explains the "Naita Akaoni" story to pupils, and the instructor asks pupils to generate questions about the material. The instructor collected the questions pupils generated at the end of the first period. Between the first and the second periods of the lesson, the instructor grouped similar questions together. As a result, four question categories were formed, revolving around each of these questions: 1 . Why does the red ogre want human friends?, 2. Why does the blue ogre sacrifice himself to help the red ogre?, 3. Why does the gentle red ogre get angry?, and 4 . Why does the blue ogre leave the village? In the second period of the lesson (45 minutes), the instructor forms pupil groups, based on the similarities of the questions they generated, to ensure that pupils discuss the same or similar issues as the question they generated.

For pupils in a "choose a question" group (class 2), in the first period of the lesson, the instructor explains the "Naita Akaoni" story to the pupils but did not ask them to generate questions about the material. In the second period of the lesson, the instructor showed the four question categories based on what the pupils in class 1 generated, and the pupils chose the question they wanted to discuss from those options. The instructor formed discussion groups based on the questions that pupils chose.

For pupils in a "teacher decides" group (class 3), in the first period of the lesson, the instructor explains the "Naita Akaoni" story to pupils but did not ask pupils to generate questions about the material. In the second period of the lesson, the instructor formed groups of pupils and assign one of the four question categories (i.e., same as the categories generated by pupils in class 1) to each group.

Based on the above procedure, the following items were measured:

1. The number of questions during the discussion (to measure pupils' critical thinking skills; cf. Kruger, 1992; Kuramori, 1999);

2. The number of opinions expressed during the discussion (to measure pupils' communicative skills; cf. Kruger, 1992; Kuramori, 1999);

3. Pupils' impressions of the lesson (to measure how engaging the lesson was). 


\section{Results}

Among the four questions categories, one-third of the pupils in the "generate questions" group (class 1) made questions that fell into either the "Why does the red ogre want human friends?," or the "Why does the blue ogre sacrifice himself to help the red ogre?" categories. Therefore, this study compared the utterances of pupils who were in groups that discussed those two question categories (class 1: $\mathrm{n}=21$, class $2: \mathrm{n}=7$, class $3: \mathrm{n}=14$ ).

With pupils' number of utterances (turn-takes in speaking) in discussing these two questions as the dependent variable, and the instruction/group and the time duration as the independent variables, a two-way repeated measures ANOVA was performed. The results showed that the main effect of the instruction/group was statistically significant $(F(2,39)=3.40, p<.05)$; the post-hoc analysis revealed that pupils in the "generate questions" group (class 1) talked more than pupils in the "choose a question" group (class 2$)(p<.05)$ (see Figure 7.1). However, the main effect of the time duration was not statistically significant $(F(7,273)=.73, n s)$. The interaction effect was statistically significant $(F(14,273)=2.01, p<.05)$, and the post-hoc analysis revealed that at 1:00 , pupils in the "generate questions" group (class 1) talked more than pupils in the "choose a question" group (class 2) and the "teacher decides" group (class 3) $(p<.05)$. Also, at 2:00 , pupils in the "generate questions" group (class 1) talked more than pupils in the "choose a question" group (class 2) $(p<.05)$ (see Figure 7.1).

\section{Quality of utterances}

This study focused especially on the number of questions and opinions that the pupils produced during the group discussion. Based on a method employed by Kuramori (1999), two raters worked together to categorize pupils' utterances

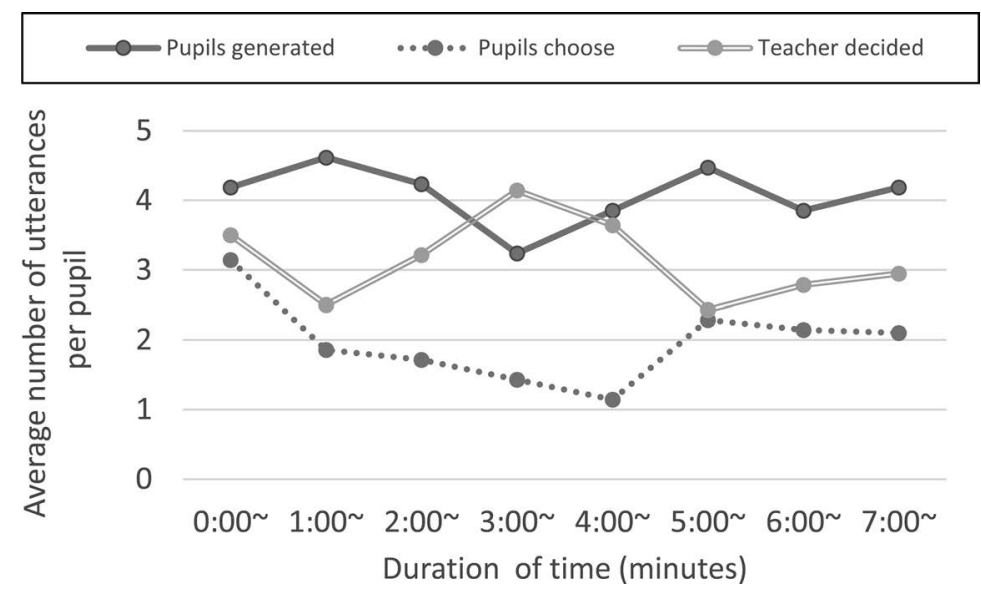

FIGURE 7.1 Average number of utterances per pupil during a discussion (in minutes). 
TABLE 7.1 Mean number of utterances per pupil for opinions and questions, according to instruction groups

\begin{tabular}{lccc}
\hline & Pupils generate $(N=21)$ & Pupils choose $(N=7)$ & Teacher decides $(N=14)$ \\
\hline Opinions & $10.76(3.65)$ & $5.14(0.38)$ & $9.36(2.40)$ \\
Questions & $2.16(0.47)$ & $0.53(0.20)$ & $1.63(0.43)$ \\
\hline
\end{tabular}

Note: Numbers in the parentheses are standard deviations.

into "opinions," "questions," and "other." When they had disagreements or differences in the categorizations, the raters continued their discussion until they could agree on one of the categories.

A one-way ANOVA was performed for the number of opinions and questions expressed during the discussion (see Table 7.1). The results showed that the number of opinions $(F(2,39)=9.46, p<.01)$ and number of questions $(F(2,39)=4.75, p<.01)$ were statistically significant, and the post-hoc analysis revealed that the pupils in the class that generated their own questions (class 1) expressed more opinions $(p<.05)$ and asked more questions $(p<.05)$ than pupils in the class that chose one of the questions from the teacher (class 2 ). The results suggest that pupils in the class generating questions were more engaged in discussions; they thought more critically (as suggested by the number of questions they asked) and communicated better (as suggested by the number of opinions they expressed) than pupils who simply chose their question from the options provided by the teacher (see Figure 7.2).

\section{Pupils' engagement with the lesson}

A hypothesis put forth in this study was that if learners discussed questions that they themselves generated during the lesson, they would be more motivated to engage with that lesson. Therefore, this section includes an analysis of the way

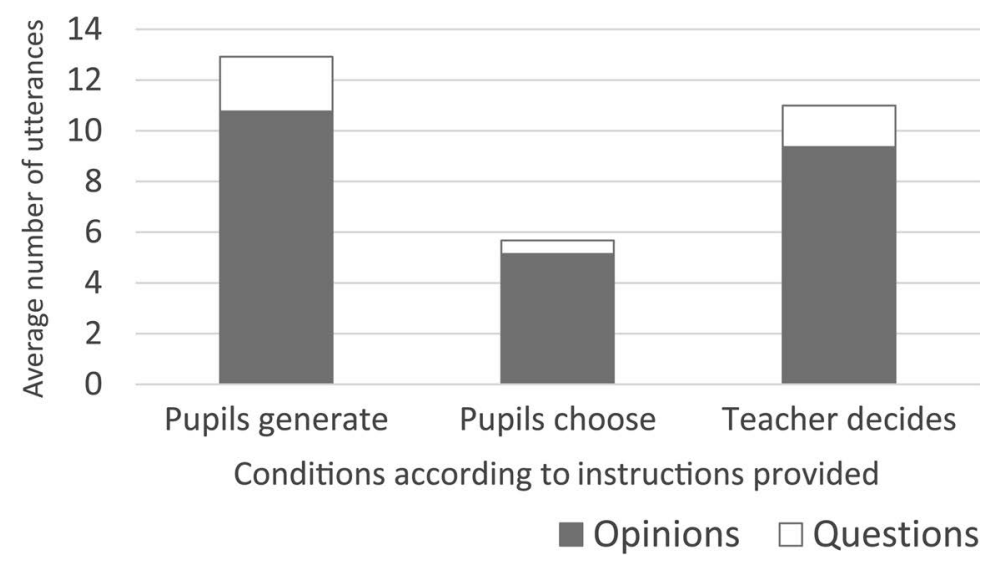

FIGURE 7.2 Average number of utterances for opinions and questions (based on instructions). 


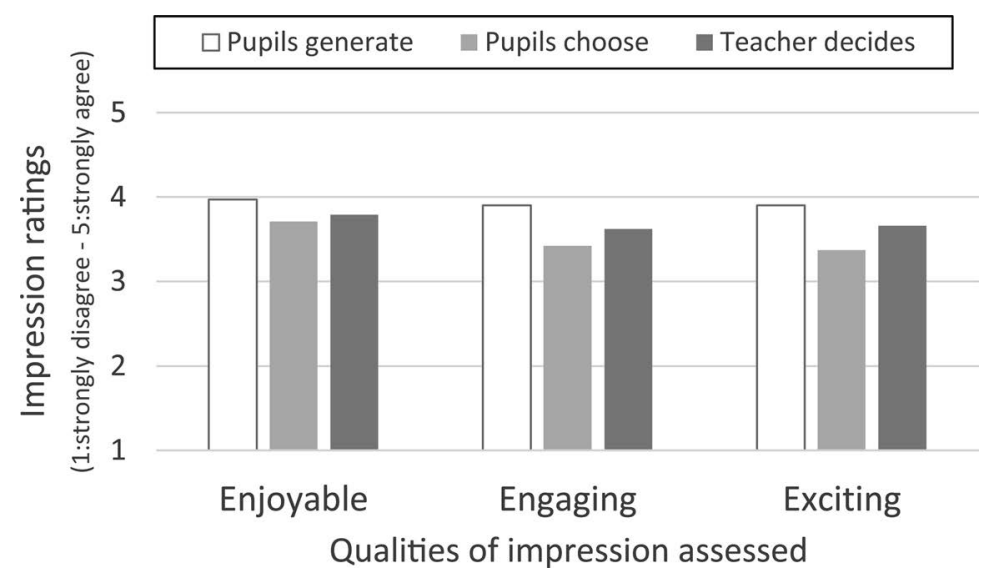

FIGURE 7.3 Pupils' impressions of the lesson (based on instructions).

QBI influenced pupils' engagement with their lesson. After the lesson, pupils rated it according to three items: "How enjoyable was the lesson?," "How engaging was the lesson?," and "How exciting was the lesson?"

The results showed that pupils in class 1 who generated their own questions had the highest ratings of all classes for the "Enjoyable," "Engaging," and "Exciting" items (see Figure 7.3). ANOVA revealed that the difference among the classes was not statistically significant for "Enjoyable" $(F(2,88)=2.14$, ns), but differences were statistically significant for "Engaging" $(F(2,88)=5.54, p<.01)$ and "Exciting" $(F(2,87)=4.32, p<.05)$. The result of post-hoc comparisons showed that the pupils in the "generate questions" group (class 1) had higher ratings for the "Engaging" and "Exciting" items than the pupils in the "choose a question" group (class 2).

\section{Discussion of Study 1 findings}

Study 1 compared three conditions in terms of group discussion questions. The results showed that pupils in the "generate a question" group (class 1) had more utterances than pupils in the "choose a question" group (class 2) during group discussions. Class 1 pupils also asked more questions and expressed more opinions during their discussions than pupils in class 2 . In addition, pupils in class 1 perceived the lesson as more engaging and more exciting than pupils in class 2 . In this study, measurements of quality and quantity relating to the discussions were compared between groups of pupils that discussed the same questions. However, only 7 out of 29 pupils in the "choose a question" group (class 2) selected the two questions that we analyzed responses to. Therefore, some caution is necessary in interpreting the 'less favorable' performance of pupils in that class.

Regarding pupils' utterances, "gaps between friends' opinions" - was manifested in the class session using "Naita Akaoni." One pupil had an opinion about 
the question, "Why does the red ogre want human friends?," and said, "The red ogre lived near the human village and wanted to invite humans to his home and entertain them." However, another pupil said, "The red ogre might have thought that if he could become friends with a human, ogres and humans could become friends." Another thought that the red ogre had a broader vision, wanting the entire ogre tribe and the human village to become friends. When there was a discrepancy among pupils, they tried to persuade classmates or reach a mutual conclusion; thus, their understanding of the material deepened and their communication skills improved.

However, the problem with QBI was that some learners generated questions unrelated to the purpose of the teaching material. For example, some pupils asked questions such as "Why were the ogres red and blue, not yellow and purple?" This kind of question is of course sometimes worth discussing. However, in most cases, it leads to endless, fruitless discussions. To ensure that learners generate appropriate debatable questions for deeper comprehension of the material and quality discussions, an instructor needs to teach learners how to refine their questions.

The main reason learners ask such questions is that they do not have a clear image regarding what the appropriate questions might be. "Appropriate" in this context means the questions that have the potential to deepen learners' understanding of the material and theme. Additionally, learners cannot generate appropriate questions when they have not been shown a sufficient number of appropriate model questions. Therefore, in the next study, the effects of showing "appropriate and inappropriate questions" to learners and explaining "why some questions are appropriate and some are not" were examined.

\section{Study 2}

The objective of Study 2 was to develop a method for training learners to generate quality questions, to promote a deeper understanding of the material and to stimulate discussion among peers.

\section{Question generation requires "model questions" and explanations}

The approach employed here was based on Wong's (1985) review, which noted that showing model examples of questions to learners is key for successful training in generating useful questions. Therefore, the hypothesis put forth in this study was that showing models of "good questions" to learners would help them imagine appropriate questions and, as a consequence, they would be able to generate content-related questions. However, an additional assumption in this study was that just showing learners good questions was not enough. It is also essential for learners to understand the nature of "good questions" through becoming aware of and understanding the reasons that make them "good questions." Therefore, the instructor should show them model questions and explain 
TABLE 7.2 Summary of the contents of the instructions provided, according to the instruction groups

Good model Bad model Explanation

1. Good question models only

2. Good question models with explanation

3. Good and bad question models with explanation

$\begin{array}{lll}0 & - & \\ 0 & 0 & 0 \\ 0 & 0 & 0\end{array}$

explicitly why they are good ones. It was also hypothesized in this study that it would be better to show learners both good and bad examples for contrast and explain why they are "good" and "bad."

Three instruction methods were compared: "showing good questions only," "showing good questions and providing an explanation," and "showing both good and bad questions and providing explanations." Table 7.2 summarizes the instructional design. It was hypothesized in this study that showing good and bad examples and providing explanations would be the most effective method for training learners to generate content-related questions.

\section{Method}

\section{Participants}

A total of 83 1st-grade elementary school pupils ( males $=44$, females $=39$ ) participated in this study. The pupils came from three different classrooms.

\section{Instructions}

Instructions encompassed three lesson periods. In the first period, pupils read material about ethics geared toward elementary school students. "Ponta and Kanta" (illustrated as two raccoons) is a "dilemma story" about friends who argue whether they should play on a dangerous playground or stop their friends who are playing there. In this study, after ensuring that pupils fully understood the material, the teacher asked them to write down as many questions as possible on a worksheet provided to them (i.e., this was the pre-questions generation test).

In the second period, three different instructions (showing good questions only, showing good questions and providing an explanation, and showing good and bad questions and providing explanations) were randomly assigned to each of the three classes. After receiving instructions, pupils practiced generating questions on new material they were provided (i.e., this was the post questions generation test). Details of the instructions are provided below.

\section{Good question models only (class $n=29$ )}

The instructor only showed learners good questions; no explanation was provided. Therefore, learners most likely did not acquire the characteristics of good 
questions. An example of a good question related to "Ponta and Kanta" is, "What is true friendship?"

\section{Good question models with explanation (class $n=30$ )}

The instructor showed learners good questions and explicitly explained the reasons for why they were "good." Therefore, learners most likely grasped the characteristics of good questions. An example of a good question is the same as above, but learners also received an explanation such as, "This is a good question because it is related to the point of the story we've read, and we can discuss it to deepen our understanding."

\section{Good and bad question models with explanation (class $n=24$ )}

The instructor showed good and bad questions and explained why those questions were considered as either "good" or "bad." An example of a good question is the same as above, and an example of a bad question is, "Why is Ponta a raccoon and not a fox?" The instructor's explanation for the assessment of this question as "bad" was: "It is a bad question because it is unrelated to the point of the story we've read, and we cannot reach any conclusion even if we discuss it."

\section{Quality of questions generated by pupils}

In the third period, the instructor asked pupils to write down as many questions as possible on another worksheet they were given. Two raters worked together to assess the quality of the questions and their relevance to the theme of the material as "related" or "unrelated." If there was incongruency between the raters, they discussed their differences until they reached consensus.

\section{Results}

The purpose of Study 2 was to develop a method for training learners to generate quality questions. Therefore, this section focuses on the number of questions generated by the pupils that were related and unrelated to the content of the material studied (see Figure 7.4).

First, a two-way mixed-design ANOVA was conducted, with the number of content related questions pupils generated at the pre- and post-test as the repeated variable and the set of instructions as the between-subjects variable. The results showed that the main effect of the test was statistically significant $(F(1,80)=15.28, p<.01)$, the main effect of the instruction was not statistically significant $(F(2,80)=2.29, n s)$, and the interaction was statistically significant $(F(2,80)=3.03, p<.05)$. The post-hoc analysis showed that "the good question models only" resulted in a decrease in the number of content related questions that the learners produced. 


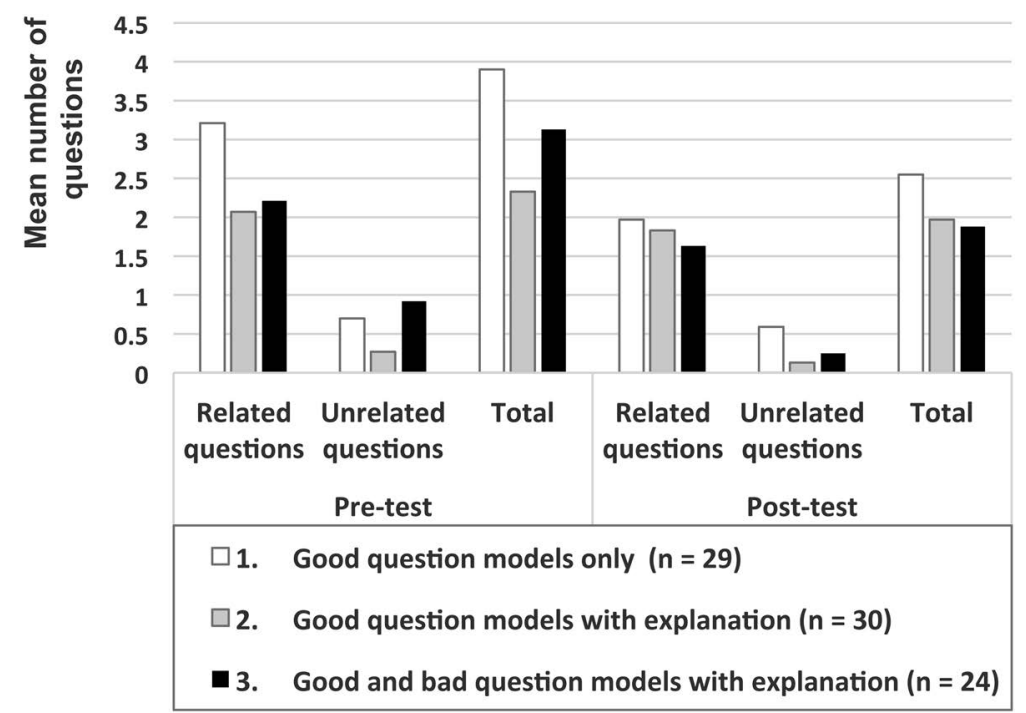

FIGURE 7.4 Mean number of content-related, unrelated, and total questions that pupils generated before and after training, according to the instruction groups.

Second, a two-way mixed-design ANOVA was conducted, with the number of content related questions pupils generated at the pre- and post-test as the repeated variable and the set of instructions as the between-subjects variable. The results showed that the main effect of the test was statistically significant $(F(1,80)=7.32, p<.01)$, the main effect of the instruction was statistically significant $(F(2,80)=3.89, p<.05)$, and the interaction was statistically significant $(F(2,80)=2.52, p<.05)$. The post-hoc analysis showed that only "the model with good and bad questions and explanations" resulted in a decrease in the number of unrelated questions.

Finally, a two-way mixed-design ANOVA was conducted, with the total number (sum of related and unrelated questions) of questions pupils generated at the pre- and post-test as the repeated variable and the set of instructions as the between-subjects variable. The results showed that the main effect of the test was statistically significant $(F(1,80)=26.26, p<.01)$, the main effect of the instruction was statistically significant $(F(2,80)=3.32, p<.05)$, and the interaction was statistically significant $(F(2,80)=2.77, p<.10)$. The post-hoc analysis showed that two instructions - "the good question models only" and "the model with good and bad questions and explanations" - resulted in a decrease in the total number of questions learners generated.

\section{Discussion of Study 2 findings}

The total number of questions that learners generated were found to decrease in both "the good question models only" and "the model with good and bad 
questions and explanations" conditions. However, in the "good question models only" condition, both content related questions and the total number of questions decreased. In contrast, in the "good and bad question models with explanation" condition, the content unrelated questions decreased, although the total number of questions also decreased. Therefore, results of Study 2 suggest that "the good question models only" was not effective in either promoting the generation of content related questions or decreasing content unrelated questions. Also, the "good question models with explanation" condition neither promoted generation of content related questions nor decreased content unrelated questions. Only the "good and bad question models with explanation" condition was found to be effective for decreasing the number of content unrelated questions that learners produce. However, further research is necessary to examine more carefully the influence of the material for which learners have to generate questions, and to reduce the possibility of instructions having a negative effect of inhibiting learners in generating questions (e.g., through concern about not generating "good enough" questions).

\section{Conclusion}

The results of Study 1 suggested that generating questions motivated pupils to find out the answers; they asked more questions in the group discussion activity and expressed more opinions. However, some pupils did not have sufficient skills to generate content-related, appropriate questions. Therefore, in Study 2, the effect of question generation training activities was examined. The result of this investigation suggested that showing pupils both good and bad examples of questions and providing explanations for those helped pupils avoid generating content unrelated questions.

The potential value of this chapter is in showing the effectiveness of QBI, which promotes pupils' positive emotions (i.e., engaging, and exciting) and pupils' positive behaviors, such as asking questions or expressing opinions during discussions.

Combining the results of Studies 1 and 2, QBI needs to include presenting good and bad question models and explanations to learners to improve their ability in generating appropriate content-related questions. Therefore, the revised QBI strategy should be as follows:

1. Ensure that learners understand the material.

2. Present good and bad question models - and explanations for those - to learners.

3. Instruct learners to generate questions.

4. Plan activities using learners' questions (e.g., discussions in a group, asking questions in a pair).

Concerning the use of learners' questions, this chapter described the use of group discussions, but other approaches - such as learners asking each other questions 
in pairs or fostering inquiry based learning based on learners' questions - are also possible for helping learners realize the importance of generating questions and promoting a deeper understanding of the materials they are studying.

Today, the lecture-style class, in which a teacher simply explains the lesson content, remains as the most frequently used instructional method at all levels of education. Teachers and learners assume that a teacher is the main agent for conveying knowledge and asking questions. This chapter emphasizes the importance of learner-generated questions in the classroom, showing how we can take advantage of such questions in the lesson so that learners become active contributors to their knowledge development.

In the 21st century, knowing a vast amount of information is less important, but how to use information is increasingly proving to be of greater value. However, this does not mean that basic knowledge or information is unnecessary. As this chapter has pointed out in QBI procedures, for learners to generate high-quality questions, it is essential that instructors take steps to ensure that learners acquire/develop adequate background information. Only by contrasting their prior knowledge with new information can learners generate appropriate questions. As we learn to appreciate more the value of question generation in education, an essential part of an instructor's role will be educating learners to ask questions and training them to learn from their questions. Therefore, $\mathrm{QBI}$ is one instructional approach that could be of genuine value to educational practitioners.

\section{References}

Graesser, A. C., \& Olde, B. A. (2003). How does one know whether a person understands a device? The quality of the questions the person asks when the device breaks down. Journal of Educational Psychology, 95(3), 524-536.

Hosoya, J. (1977). Dai shizen no chiteki tanken ni okeru "Kimari" no yakuwari [The role of laws in intellectual discovery in the great nature]. Kyoka Kenkyu Shougakkou Rika [Subject Study: Elementary School Science], 59, 1-5.

Ikuta, J., \& Maruno, S. (2005). Sitsumon dukuri wo chushin ni shita shidou ni yoru jido no jyugyo shu no sitsumon seisei katudo no henka [Change of children questioning in elementary school class through question generation centered instruction]. Japanese Society for Educational Technology, 29, 577-586.

King, A. (1989). Effects of self-questioning training on college-students comprehension of lectures. Contemporary Educational Psychology, 14(4), 366-381.

King, A. (1991). Effects of training in strategic questioning on children's problem-solving performance. Journal of Educational Psychology, 83(3), 307-317.

King, A. (1992). Comparison of self-questioning, summarizing, and notetaking-review as strategies for learning from lectures. American Educational Research Journal, 29(2), 303-323.

Kuramori, M. (1999). Analysis of the negotiation process: Influence of elementary school children's attitudes on the negotiation process and their performance in discussion. Japanese Journal of Educational Psychology, 47, 121-130.

Kruger, A. C. (1992). The effect of peer and adult-child transactive discussions on moral reasoning. Merrill-Palmer Quarterly, 38, 191-211. 
Miyake, N., \& Norman, D. A. (1979). To ask a question, one must know enough to know what is not known. Journal of Verbal Learning and Verbal Behavior, 18(3), 357-364.

Otero, J., \& Graesser, A. C. (2001). PREG: Elements of a model of question asking. Cognition and Instruction, 19(2), 143-175.

Otero, J. (2009). Question generation and anomaly detection in texts. In D. J. Hacker, J. Dunlosky, \& A. C. Graesser (Eds.), Handbook of metacognition in education (pp. 47-59). New York: Routledge

Oyama,Y. (2017). Promoting learners' spontaneous use of effective questioning Integrating research findings inside and outside of Japan. In E. Manalo, Y. Uesaka, \& C. Chinn (Eds.), Promoting spontaneous use of learning and reasoning strategies: Theory, research, and practice for effective transfer. London, England: Routledge.

Rosenshine, B., Meister, C., \& Chapman, S. (1996). Teaching students to generate questions: A review of the intervention studies. Review of Educational Research, 66(2), 181-221.

Wong, B.Y. L. (1985). Self-questioning instructional-research: A review. Review of Educational Research, 55(2), 227-268.

Yuzawa, M. (2009). Jiko sitsumon seisei ni yorukastuyou ryoku no koujyo [Improvement of application skill thorough self-question generation]. In H.Yoshida, \& E. De Corte (Eds.), Application of children' logic into classroom practice: Educational practical psychology in designing class. Kyoto, Japan: Kitaouji Shobou. 